\title{
Determinants of cord blood adipokines and association with neonatal abdominal adipose tissue distribution
}

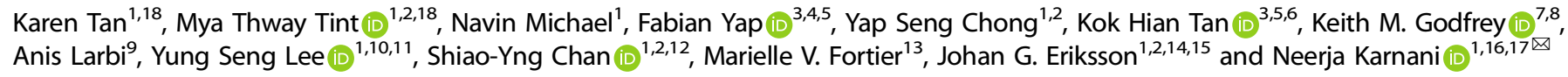

(c) The Author(s) 2021

BACKGROUND: Cord blood leptin and adiponectin are adipokines known to be associated with birth weight and overall infant adiposity. However, few studies have investigated their associations with abdominal adiposity in neonates. We examined maternal factors associated with cord blood leptin and adiponectin, and the association of these adipokines with neonatal adiposity and abdominal fat distribution measured by magnetic resonance imaging (MRI) in an Asian mother-offspring cohort.

METHODS: Growing Up in Singapore Towards healthy Outcomes (GUSTO), is a prospective mother-offspring birth cohort study in Singapore. Cord blood plasma leptin and adiponectin concentrations were measured using Luminex and Enzyme-Linked Immunosorbent Assay respectively in 816 infants. A total of 271 neonates underwent MRI within the first 2-weeks after delivery. Abdominal superficial (sSAT), deep subcutaneous (dSAT), and intra-abdominal (IAT) adipose tissue compartment volumes were quantified from MRI images. Multivariable regression analyses were performed.

RESULTS: Indian or Malay ethnicity, female sex, and gestational age were positively associated with cord blood leptin and adiponectin concentrations. Maternal gestational diabetes (GDM) positively associated with cord blood leptin concentrations but inversely associated with cord blood adiponectin concentrations. Maternal pre-pregnancy body mass index (BMI) showed a positive relationship with cord blood leptin but not with adiponectin concentrations. Each SD increase in cord blood leptin was associated with higher neonatal SSAT, dSAT and IAT; differences in SD $(95 \% \mathrm{CI}): 0.258(0.142,0.374), 0.386(0.254,0.517)$ and $0.250(0.118$, 0.383), respectively. Similarly, each SD increase in cord blood adiponectin was associated with higher neonatal sSAT and dSAT; differences in SD $(95 \% \mathrm{Cl}): 0.185(0.096,0.274)$ and $0.173(0.067,0.278)$, respectively. The association between cord blood adiponectin and neonatal adiposity was observed in neonates of obese mothers only.

CONCLUSIONS: Cord blood leptin and adiponectin concentrations were associated with ethnicity, maternal BMI and GDM, sex and gestational age. Both adipokines showed positive association with neonatal abdominal adiposity.

International Journal of Obesity (2022) 46:637-645; https://doi.org/10.1038/s41366-021-00975-3

\section{INTRODUCTION}

Adipokines are hormones secreted by adipocytes and suggested to play important roles in energy homeostasis and cell metabolism [1]. Leptin, a peptide hormone produced by adipocytes in proportion to their triglyceride content, connects fat stores with the central control of energy balance [2]. Although leptin deficiency results in increased food intake and decreased energy expenditure [3], most obese individuals have elevated leptin concentrations which is thought to be a leptin resistant state [2]. Adult leptin concentrations are higher in Indians and Malays compared to Chinese [4]. Many studies have shown positive associations of cord blood leptin and birth weight [5-10]. Maternal characteristics, such as obesity [7], smoking [10] and glucose concentrations [11], have been associated with increased cord

\footnotetext{
${ }^{1}$ Singapore Institute for Clinical Sciences (SICS), Agency for Science, Technology and Research (A*STAR) Singapore, Singapore, Singapore. ${ }^{2}$ Human Potential Translational

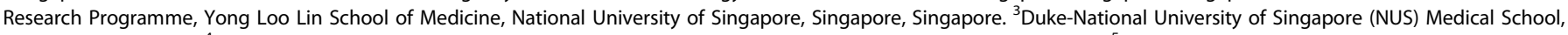
Singapore, Singapore. ${ }^{4}$ Department of Pediatric Endocrinology, KK Women's and Children's Hospital, Singapore, Singapore. ${ }^{5}$ National Technological University (NTU)-Lee Kong Chian School of Medicine, Singapore, Singapore. ${ }^{6}$ Department of Maternal Fetal Medicine, KK Women's and Children's Hospital, Singapore, Singapore. ${ }^{7}$ MRC Lifecourse Epidemiology Unit, University of Southampton, Southampton, United Kingdom. ${ }^{8} \mathrm{NIHR}$ Southampton Biomedical Research Centre, University of Southampton \& University Hospital, Southampton, United Kingdom. ${ }^{9}$ Singapore Immunology Network (SlgN), Agency for Science, Technology and Research (A*STAR), Singapore, Singapore. ${ }^{10}$ Department

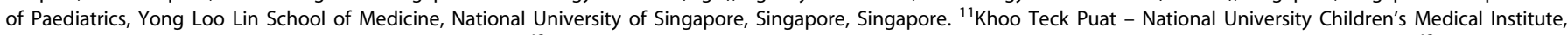
National University Health System, Singapore, Singapore. ${ }^{12}$ Department of Obstetrics and Gynaecology, National University Hospital, Singapore, Singapore. ${ }^{13}$ Department of Diagnostic and Interventional Imaging, KK Women's and Children's Hospital, Singapore, Singapore. ${ }^{14}$ Folkhälsan Research Center, Helsinki, Finland. ${ }^{15}$ Department of General Practice and Primary Health Care, University of Helsinki, Helsinki, Finland. ${ }^{16}$ Department of Biochemistry, Yong Loo Lin School of Medicine, National University of Singapore,

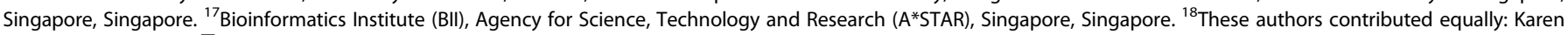
Tan, Mya Thway Tint. ${ }^{凶}$ email: neerja_karnani@sics.a-star.edu.sg
}

Received: 21 December 2020 Revised: 9 September 2021 Accepted: 22 September 2021

Published online: 4 December 2021 
blood leptin concentrations. Fetal leptin has been proposed to influence the programming of hypothalamic neuronal networks to influence adiposity in the long term [12]. Several studies have examined the association of cord blood leptin with adiposity in later childhood $[8,13-16]$ and a report has suggested that this association changes as the child grows with age [14].

Adiponectin, one of the adipokines produced by adipocytes, mediates communication of the adipose tissue with other metabolic tissues such as the liver and skeletal muscle [17]. Adiponectin suppresses hepatic gluconeogenesis and promotes insulin sensitization in adults $[17,18]$. In adults, lower adiponectin concentrations are associated with adverse metabolic parameters such as greater adiposity, insulin resistance and gestational diabetes mellitus (GDM) [18-20], and Indian ethnicity compared to Malay and Chinese [21]. On the other hand, prenatal exposures such as maternal obesity [22] and GDM status [23] have been associated with higher cord blood adiponectin concentrations. Cord blood adiponectin concentration was shown to be positively associated with cord blood leptin concentration, fetal growth and birthweight [9, 24-26], and fetal adiponectin concentration is higher than adult adiponectin concentration [27, 28]. Maternal adiponectin concentrations have shown to be inversely associated with offspring's birth weight and adiposity measures [20, 29, 30]. During pregnancy, adiponectin levels decrease as the mother develops an insulin-resistant state to support reduced glucose uptake and increased lipolysis, shifting nutrients such as glucose and lipids to the fetus $[29,31]$. A high concentration of adiponectin in the fetus may enhance the growth-promoting effect of insulin through its insulin-sensitizing action [9]. Studies in mice have shown that fetal adiponectin enhances fetal fat deposition and plays a role in maternal obesity-induced increased birth weight [32].

Increased abdominal adiposity (AA) is a known independent risk factor for adverse cardio-metabolic outcomes in adults [33]. Increased visceral fat deposition in older children and adolescents has also been associated with insulin resistance, and an increased risk of cardiovascular disease and diabetes [34, 35]. South Asians are characterized by greater abdominal obesity and higher insulin resistance as compared to Caucasians of similar body mass index (BMI) [36]. We have observed differential distribution of abdominal adipose tissue compartments (AAT) in neonates among Asian ethnic groups in Singapore [37], with higher abdominal subcutaneous adipose tissue among Indian neonates despite lower birth weight. This finding is in line with the notion that Indian newborns are born light but with higher body fat [38]. With the increasing prevalence of childhood obesity [39] and the prevalence of metabolic syndrome among children and adolescents [40], it is important to better understand the early life factors influencing $A A$.

Both cord blood leptin and adiponectin have been reported to be positively associated with birth weight and overall adiposity at birth measured mostly by simple anthropometry such as BMI and skinfold thickness $[6,7,9-11,14,24,25,28]$. However, although leptin is known to be correlated with AA [13-16], few of these studies have included more accurate measurements of AA compartment volumes by MRI in early infancy. This study aimed to determine [1] maternal and fetal determinants of cord blood leptin and adiponectin concentrations in Asian neonates, and [2] the association between cord blood leptin and adiponectin concentrations and $A A$, as measured by MRI, in early infancy in a multi-ethnic Asian prospective cohort.

\section{METHODS}

\section{Study design and population}

The study was based on mother-offspring pairs from the Growing Up in Singapore Towards healthy Outcomes (GUSTO) study, a prospective cohort study in Singapore [41]. Pregnant women aged 18 years and above were recruited between June 2009 and September 2010 during the first trimester of pregnancy $(<14$ weeks' gestation based on dating ultrasound scan) from two public maternity units in Singapore; KK Women's and Children's Hospital (KKH) and National University Hospital (NUH). This study was approved by the Institutional Review Board of the Singapore National Healthcare Group and the Central Institutional Review Board of Singhealth. Parents of the neonates provided voluntary written consent for the study. This study was registered at clinicaltrials.gov as NCT01174875.

\section{Maternal characteristics}

Demographic data, lifestyle, obstetric and medical history were collected at multiple study visits using interviewer administered questionnaires and from hospital records. Self-reported pre-pregnancy weights of mothers were recorded. Pre-pregnancy body mass index (ppBMI) was calculated from the self-reported pre-pregnancy weight and measured height at booking. ppBMI categories were defined using WHO recommended $\mathrm{BMI}$ cutoff points for Asians [42]. Pregnant women underwent a $2 \mathrm{~h} 75 \mathrm{~g}$ oral glucose tolerance test (OGTT) at 26-28 weeks gestation. Glucose concentrations were measured using hexokinase method (Advia 2400 Chemistry system (Siemens Medical Solutions Diagnostics) and Beckman LX20 Pro analyzer (Beckman Coulter)). GDM was diagnosed using 1999 World Health Organization (WHO) criteria: $\geq 7.0 \mathrm{mmol} / \mathrm{L}$ for fasting plasma glucose or $\geq 7.8 \mathrm{mmol} / \mathrm{l}$ for $2 \mathrm{~h}$ post-prandial glucose [43]. Gestational weight gain (GWG) groups were defined by 1990 Institute of Medicine guidelines (IOM) for rates of weight gain in the second and third trimester per week [44].

\section{Infant measurements}

Information on birth weight, birth length, and head circumference were obtained from medical records. Triceps and subscapular skinfolds were measured on the right side in triplicates to the nearest $0.2 \mathrm{~mm}$ using Holtain skinfold calipers (Holtain Ltd, Crymych, UK). The validated GUSTO equation for estimating fat mass (Fat Mass GUSTO $=-0.022+(0.307 \times$ weight $)-(0.077 \times$ gender $)+(0.028 \times$ subscapular skinfolds $)-(0.019 \times$ gestational age), where gender $=1$ for male, 0 for female) was used to calculate fat mass [45]. The PEA POD Infant Body Composition System Version 3.1.0 (Cosmed, Italy) was used to measure body composition, i.e., fat mass and fat free mass $[46,47]$. After excluding neonates whose parents did not consent for PEA POD measurement, and those that had $<2.5 \mathrm{~kg}$ birthweight, $<5 \%$ percent body fat in PEA POD ${ }^{\circ}$ assessment [45], and no cord blood adipokines measured, a total of 259 neonates remained for subsequent analysis on PEA POD ${ }^{\circ}$ - adipokine association. Clothing was removed from the infant and the infant was placed on the scale for body mass measurement and inside the chamber for body volume measurement. Percent body fat was computed by the PEA POD system. Age and sex-specific densities of free fat mass based on multi-compartment studies are used by the PEA POD ${ }^{\circ}$ [45].

\section{Cord blood adipokine concentrations}

Umbilical cord blood leptin was measured in EDTA plasma from venous cord blood using the Procarta-5-plex-DropArray Luminex assay. The coefficient of variation (CV) of a pooled plasma control was $17.3 \%$. Umbilical cord blood total adiponectin was measured in EDTA plasma from venous cord blood using the Adiponectin Human in vitro ELISA (EnzymeLinked Immunosorbent Assay) kit (Abcam). The CV of a pooled plasma control was $13.3 \%$. Adjustment for plate effect was performed using median centering where the median of each plate was shifted to the global median for all plates.

\section{Quantification of abdominal adipose tissue compartments}

333 healthy neonates born $\geq 34$ weeks gestation with birth weight $(B W) \geq$ $2000 \mathrm{~g}$ had abdominal adipose tissue compartment (AAT) volumes data available from MRI scans performed within two weeks post-birth. A detailed participant selection flow chart can be accessed from Tint MT et al. [37]. Of these 333 neonates, cord blood adipokines data was available for 271 neonates. Briefly, non-sedated neonates were placed in an immobilization bag within an adult head coil. The abdomen was scanned from the diaphragm to the symphysis pubis. T1-weighted water-suppressed (WS) and non-WS axial fast-spin echo sequences were acquired by GE Signa HDxt 1.5 tesla magnetic resonance scanner (GE Healthcare). Pulse and oxygen saturation amounts of the neonate were monitored in the presence of a neonatologist. WS images were processed to yield quantitative values of AAT volumes. Non-WS images were used to assist 
Table 1. Factors associated with cord blood leptin and adiponectin.

\begin{tabular}{|c|c|c|c|c|c|}
\hline & $N=565$ & $\begin{array}{l}\text { Cord blood Leptin } \\
\beta(95 \% \mathrm{Cl})\end{array}$ & $P$ & $\begin{array}{l}\text { Cord blood Adiponectin } \\
\beta(95 \% \mathrm{Cl})\end{array}$ & $P$ \\
\hline \multicolumn{6}{|l|}{ Ethnicity } \\
\hline Chinese & 285 & Reference & & Reference & \\
\hline Malay & 170 & $0.229(0.027,0.431)$ & 0.026 & $0.268(0.050,0.486)$ & 0.016 \\
\hline Indian & 110 & $0.628(0.409,0.847)$ & $<0.001$ & $0.213(-0.023,0.449)$ & 0.076 \\
\hline \multicolumn{6}{|l|}{ Gestational diabetes mellitus (GDM) } \\
\hline \multicolumn{6}{|l|}{ Mother pre-pregnancy BMI category } \\
\hline $\mathrm{BMI}<18.5 \mathrm{~kg} / \mathrm{m}^{2}$ & 61 & $-0.048(-0.315,0.219)$ & 0.724 & $-0.002(-0.292,0.287)$ & 0.989 \\
\hline BMI $18.5-22.9 \mathrm{~kg} / \mathrm{m}^{2}$ & 281 & Reference & & Reference & \\
\hline BMI $23.0-24.9 \mathrm{~kg} / \mathrm{m}^{2}$ & 74 & $0.256(0.009,0.504)$ & 0.042 & $-0.074(-0.340,0.192)$ & 0.586 \\
\hline $\mathrm{BMI} \geq 25.0 \mathrm{~kg} / \mathrm{m}^{2}$ & 149 & $0.143(-0.067,0.352)$ & 0.182 & $0.196(-0.029,0.422)$ & 0.088 \\
\hline Female & 274 & $0.379(0.221,0.536)$ & $<0.001$ & $0.254(0.084,0.423)$ & 0.003 \\
\hline \multicolumn{6}{|l|}{ Education } \\
\hline Primary & 26 & $0.079(-0.336,0.494)$ & 0.708 & $-0.315(-0.763,0.132)$ & 0.400 \\
\hline Secondary & 369 & $0.122(-0.069,0.312)$ & 0.210 & $0.061(-0.144,0.267)$ & 0.559 \\
\hline Tertiary & 170 & Reference & & Reference & \\
\hline \multicolumn{6}{|l|}{ Tobacco Exposure } \\
\hline No exposure & 285 & Reference & & Reference & \\
\hline Exposed with cotinine level <level of detection & 173 & $0.213(-0.259,0.685)$ & 0.376 & $0.036(-0.472,0.544)$ & 0.890 \\
\hline Exposed with cotinine level $<14 \mathrm{ng} / \mathrm{ml}$ & 89 & $0.045(-0.203,0.293)$ & 0.720 & $0.092(-0.175,0.360)$ & 0.497 \\
\hline Exposed with cotinine level $\geq 14 \mathrm{ng} / \mathrm{ml}$ & 18 & $0.048(-0.145,0.241)$ & 0.625 & $0.060(-0.148,0.269)$ & 0.570 \\
\hline Excessive & 302 & $0.074(-0.111,0.259)$ & 0.433 & $0.059(-0.140,0.259)$ & 0.560 \\
\hline Maternal Age (Years) & 565 & $0.011(-0.006,0.028)$ & 0.219 & $0.002(-0.017,0.020)$ & 0.875 \\
\hline
\end{tabular}

Standardized scores of cord blood leptin and adiponectin as outcomes. Coefficients $(\beta)$ are change in independent variables with $95 \%$ confidence intervals $(95 \% \mathrm{Cl})$ per standardized score value change in cord blood leptin or adiponectin. $P$ values were determined with the use of multivariable regression models. Models are mutually adjusted for ethnicity, maternal education, tobacco exposure, parity, maternal age, maternal pre-pregnancy BMI categories, gestational weight gain (GWG) categories based on 1999 the Institute of Medicine (IOM) guideline, gestational diabetes mellitus (GDM) status, gestational age at delivery and child's sex.

in the localization of anatomical structures if necessary. The AAT was categorized into superficial (sSAT), deep (dSAT) subcutaneous and internal (IAT) adipose tissue. MRI images were processed by an in-house semiautomated quantitative analysis algorithm using MATLAB 7.13 software (The MathWorks Inc., Natick, Massachusetts, USA). All MRI images were analyzed by a physician and an experienced magnetic resonance analyst.

\section{Statistical analysis}

The characteristics of mothers and offspring were compared among the whole cohort vs. MRI and PEAPOD ${ }^{\circ}$ subsets using independent sample $T$ tests for continuous variables and chi square tests for categorical variables. Cord blood leptin and adiponectin concentrations were not normally distributed thus Mann-Whitney $U$ tests were used for group comparison.

Multivariable regression analyses were performed to determine maternal and neonatal factors associated with cord blood adipokines. Outcome variables i.e., adipokine concentrations were transformed into standardized scores so that the strength of associations were comparable in regression model. Models were mutually adjusted for ethnicity, maternal education, tobacco exposure, parity, maternal age, maternal pre-pregnancy BMI, GWG categories, GDM status, gestational age at delivery and child's sex.

Multivariable regression analyses were performed with cord blood adipokines (leptin and adiponectin) as the main exposures, birth weight, skinfold thickness measurement as total adiposity measure and AAT compartment volumes as outcomes of interest. All exposures and outcome variables were transformed into standardized scores so that observed strength of associations were comparable. Covariates were controlled for based on prior knowledge from the literature about factors that might confound the associations between maternal and cord adipokines and neonatal adiposity. Models were adjusted for ethnicity, pre-pregnancy BMI, GDM status, gestational age at delivery, and child's sex and birth length. When studying neonatal adiposity by MRI, models were additionally adjusted for age on MRI day. $P$ values were corrected using Benjamini-Hockberg method with false discovery rate of $0.05(25)$ [48]. 
All statistical analyses used SPSS Statistics for Windows, Version 23.0. (IBM Corp., Armonk, NY).

\section{RESULTS}

\section{Distribution of cord blood adipokines}

A flow chart of this study is shown in Supplementary Fig. 1. The characteristics of the study participants (whole cohort vs. MRI and PEA POD subsets) are shown in Supplementary Table 1. The mothers of the neonates who underwent MRI and PEA POD measurements were slightly younger, with lower $2 \mathrm{~h}$ post-OGTT glucose concentrations compared to mothers of the neonates who did not undergo MRI and PEA POD measurements, and with a greater proportion of Malay participants, more mothers who smoked, and a lower proportion of mothers with higher education. Cord blood leptin concentrations ranged from 0.3 to $20.4 \mathrm{ng} / \mathrm{mL}$ and cord adiponectin concentrations from 0.3 to $28.4 \mu \mathrm{g} / \mathrm{mL}$. There was a positive correlation between cord leptin and adiponectin $(r=0.103, p=0.003)$.

Factors associated with cord blood adipokine concentrations Factors associated with cord blood leptin and adiponectin are shown in Table 1. Female sex and longer gestation were associated with higher cord blood leptin and adiponectin concentrations. Indian and Malay neonates had higher cord blood leptin concentrations compared to Chinese neonates, while Malay neonates had higher cord blood adiponectin concentrations compared to Chinese neonates. Infants of mothers with GDM had higher cord blood leptin concentrations but lower cord blood adiponectin concentrations compared to those offspring of mothers without GDM. In addition, mothers with $\mathrm{ppBMI}$ in the overweight category had neonates with higher cord blood leptin concentrations.

\section{Associations between cord blood adipokines and neonatal adiposity}

Table 2 shows the associations between cord adipokines and neonatal adiposity. Higher cord blood leptin and adiponectin concentrations were associated with higher birth weight, skinfold thicknesses, fat mass, and higher AAT measured by MRI. Each SD increase in cord blood leptin was associated with a $0.212(0.259$, $0.266)$ SD increase in birth weight and a $0.378(0.237,0.519)$ SD increase in fat mass in the neonates. Each SD increase in cord blood leptin was associated with $0.258(0.142,0.374), 0.386(0.254,0.517)$ and $0.250(0.118,0.383)$ SD increases in SSAT, dSAT and IAT, respectively.

Similarly, each SD increase in cord blood adiponectin was associated with a $0.110(0.059,0.162)$ SD increase in birth weight and a $0.136(0.014,0.257)$ SD increase in fat mass by PEAPOD in neonates. Each SD increase in cord blood adiponectin was associated with $0.185(0.096,0.274), 0.173(0.067,0.278)$ and $0.092(-0.011$, $0.195)$ SD increases in neonatal SSAT, dSAT and IAT, respectively.

Table 3 shows the associations between cord adipokines and neonatal adiposity stratified by maternal BMl categories; underweight, normal weight, overweight and obese. Neonates of mothers of all BMI categories showed a significant positive association between cord leptin concentrations and birth weight as well as measures of neonatal adiposity. In contrast, only neonates of obese mothers with $\mathrm{BMI} \geq 25 \mathrm{~kg} / \mathrm{m}^{2}$ showed statistically significant positive association between cord adiponectin concentrations and birthweight as well as measures of neonatal adiposity. The interaction term was significant $(p<0.05)$ for the interaction between obese maternal BMI category and the cord adiponectin concentrations in the association with predicted fat mass and sSAT (Table 3).

\section{DISCUSSION}

In this study, we examined the factors associated with cord blood leptin and adiponectin concentrations and studied the

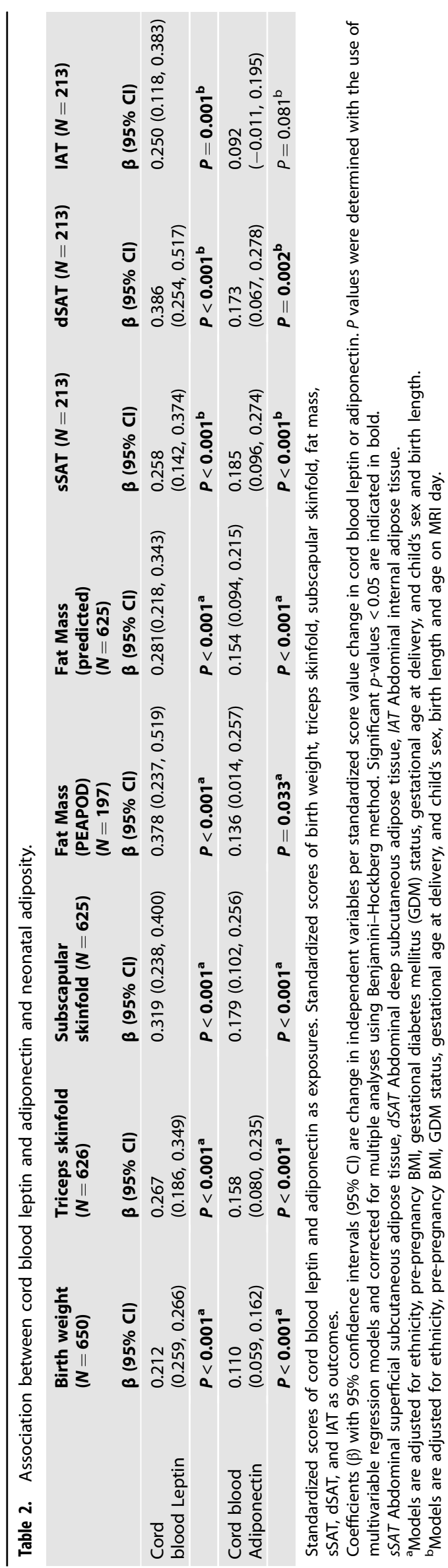




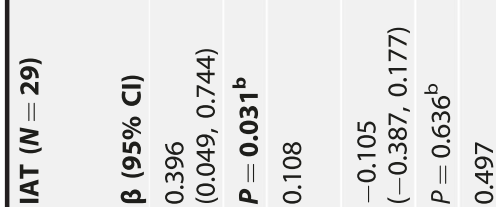

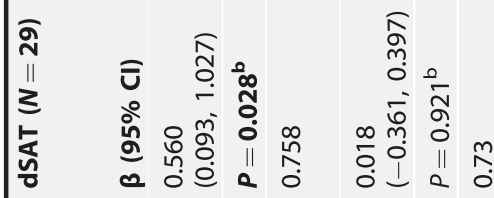

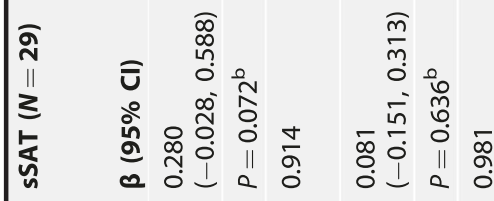

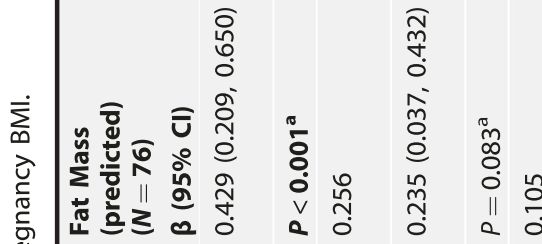

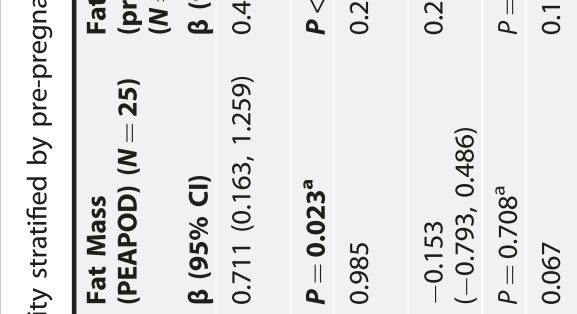

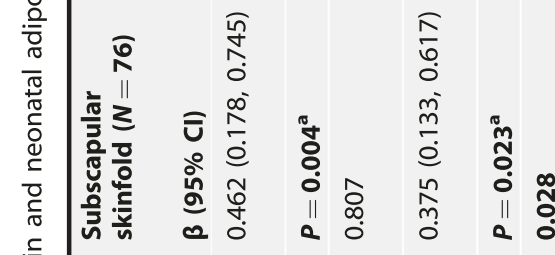

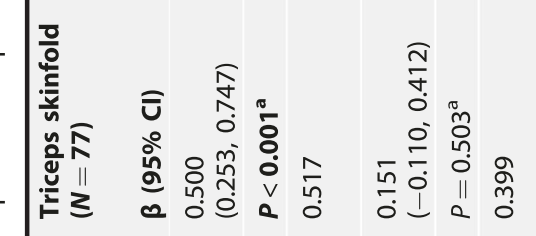

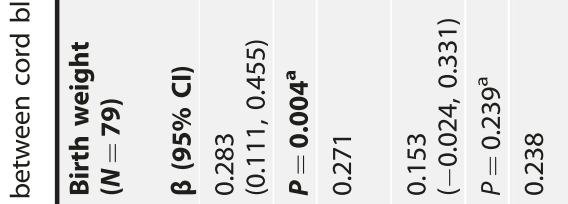

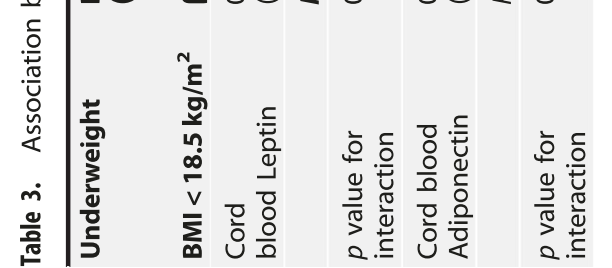

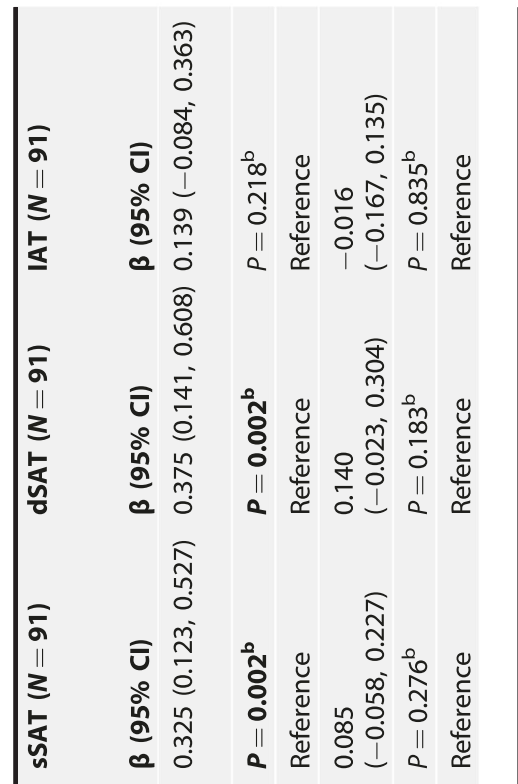

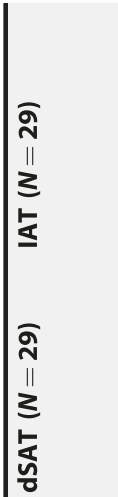

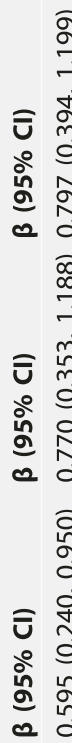

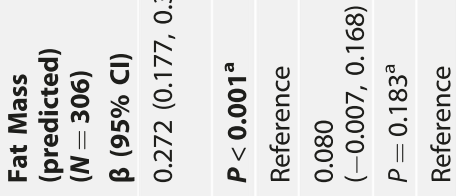

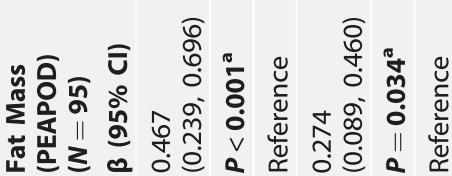

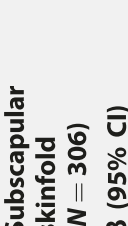

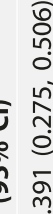

(1)

กิ

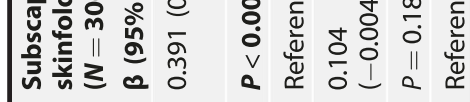

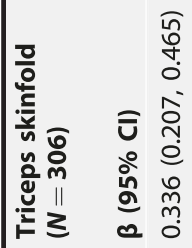

ळ

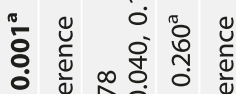

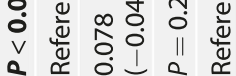

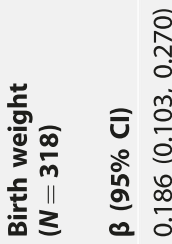

సิ

๘ँ

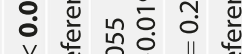

â a

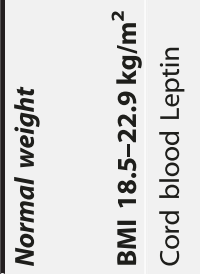

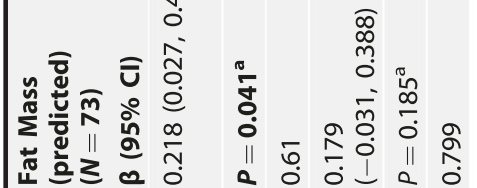

ฉิ

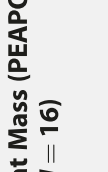

茫茷

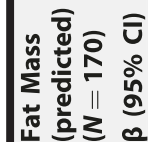

ฉิ

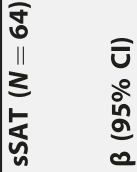

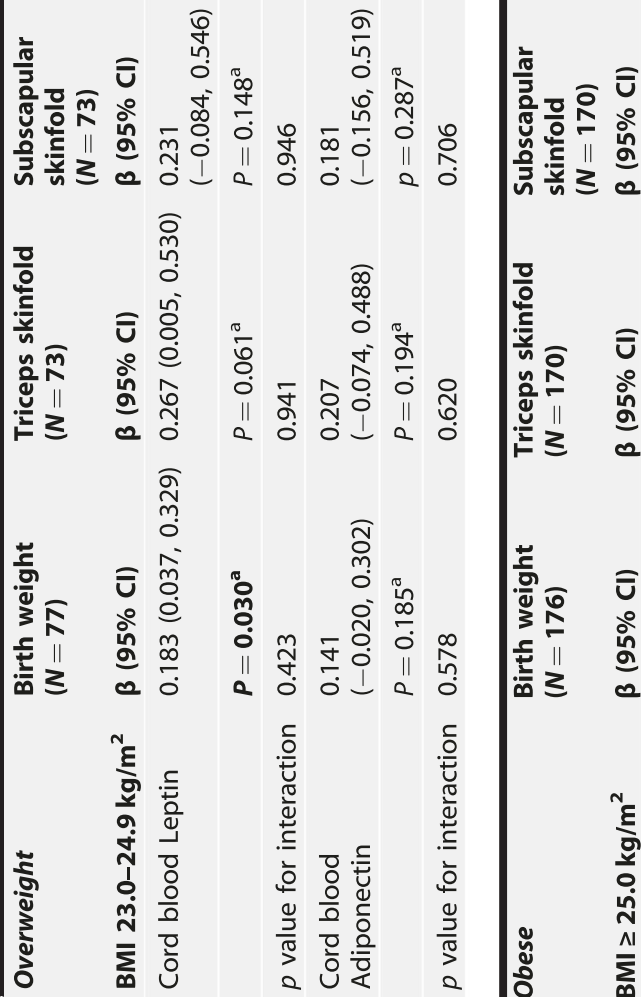


association between cord adipokines and neonatal AA. We found that sex, ethnicity, gestational age, maternal adiposity and GDM were associated with cord blood adipokine concentrations and both cord leptin and adiponectin associated positively with neonatal AA.

Maternal GDM was associated with higher cord blood leptin but lower cord blood adiponectin concentrations, similar to previous reports [49-51]. This is consistent with our previous findings that maternal glycaemia is an important determinant of neonatal adiposity [52]. We have observed a positive association between maternal glycemia and neonatal AA across a continuum of glucose levels [52], and postulate that fetal adipokines may play a role in the association between maternal glycaemia and neonatal AA status. Maternal hyperglycemia is linked to fetal hyperinsulinemia and risk of obesity in later life [53]. Our finding that maternal gestational diabetes associates with cord adipokines suggest fetal programming of fetal adipocytes by maternal hyperglycemia. Maternal glycemia is associated with increased maternal leptin, which may contribute to increased cord blood leptin and fetal growth [54]. On the other hand, high maternal glycemia increases maternal insulin resistance, and the reduced insulin signaling may contribute to reduced fetal growth which triggers an increase in fetal adiponectin concentration [31].

We observed ethnic differences in both cord blood leptin and adiponectin concentrations. Cord blood leptin concentrations were higher in Indian neonates compared to Chinese neonates, while cord blood adiponectin concentrations were higher in Malay neonates compared to Chinese neonates. Perhaps this reflects our previous observations in the GUSTO cohort that Indian and Malay neonates had greater metabolically active dSAT volumes compared to Chinese neonates [37]. The ethnic differences in adipokines may in part contribute to observed differences in neonatal adiposity between ethnic groups.

We found that female neonates had higher concentrations of both leptin and adiponectin in cord blood compared to male neonates. This aligns with our finding that female infants have higher sSAT and dSAT volumes than male infants [37]. Most studies have reported higher cord leptin but not cord blood adiponectin concentrations in female infants $[53,55,56]$.

The positive association between cord blood leptin concentrations and neonatal adiposity in this study is consistent with previous studies on birth weight and other measures of adiposity $[5,9,55]$. The production of leptin by the placenta in early fetal development suggests that besides being an indicator of fetal adipose tissue, leptin plays an important role in fetal growth [9]. The association between cord blood leptin concentration and neonatal adiposity was stronger than that for cord blood adiponectin concentration in this study, similar to other studies $[13,14,55]$. The strongest associations among all the adiposity outcomes was between dSAT and fat mass and cord blood leptin concentrations. dSAT is most metabolically active and similar to visceral fat, as well as highest in Indians [37], therefore higher cord blood leptin may predispose the neonate to increased metabolic risk in future. Unlike in adults, higher cord blood adiponectin was associated with higher neonatal adiposity. However, our findings are consistent with previous studies $[9,55,57,58]$. The lack of association between cord adiponectin and IAT is interesting as it is consistent with studies showing an association between adiponectin with subcutaneous fat rather than visceral fat $[59,60]$.

The positive association between cord blood adiponectin concentrations and neonatal adiposity in this study is also consistent with previous studies [9, 24-28]. The mechanism for the positive association between adiponectin and adiposity in the neonate compared to a negative association in adults is still unknown, and may be due to differences in metabolic function of adipocytes and secretion of adipokines [24]. Cord blood leptin and adiponectin correlated positively with each other, suggesting that fetal leptin may play a role in the secretion of adiponectin in the 
fetus, which then act in synergy to regulate fetal growth [9]. The observation that cord adiponectin associated with higher birthweight and neonatal adiposity only in obese mothers suggests that the associations may be different between women who become pregnant when obese and those who become pregnant when lean. Women who are obese may have higher insulin resistance corresponding to enhanced allocation of nutrients to the fetus [31]. The increased adiponectin in the cord blood may then enhance the growth-promoting effect of insulin through its insulin-sensitizing action, resulting in increased birthweight and adiposity [9]. Cord adipokines are likely associated with multiple pathways that influence fetal growth and the mechanisms by which maternal obesity influences these pathways require further investigation in human studies.

Other studies have described the positive association between cord blood adipokines and adiposity in early childhood [13-16, 24, 25, 55]. However several studies suggested that cord blood adipokines may not predict later childhood obesity [1315 , 25]. Longitudinal studies with follow-up of the GUSTO children are needed to explore the association between cord adipokines and childhood growth and adiposity. High molecular weight adiponectin (HMW adiponectin) is thought to be a better predictor of obesity related metabolic parameters in children $[61,62]$. In this study only total adiponectin was measured, however HMW adiponectin has been shown to be a major contributor to total adiponectin in cord blood and cord HMW adiponectin and total adiponectin have been shown to correlate well with each other $[25,63,64]$.

Our study is one of the first to use MRI to quantify AAT compartments in early infancy. GUSTO is a prospective study of Asian mothers and offspring pairs, including three Asian ethnic populations (Chinese, Malays, Indians) covering around $50 \%$ of the global population. While most previous studies used total adiposity of offspring in association with adipokine concentrations, we used AAT quantified from MRI, an accurate method without radiation to quantify $A A$, which has been shown to be related to metabolic health. The timing of MRI scans for neonates was within 2-weeks after delivery thus the observation would largely reflect the developmental influences on the offspring before any postnatal environmental exposures.

Our study has some limitations. One is that only a subset of eligible neonates whose parents gave consent for their MRI were included in the study on AA, so care therefore should be taken not to generalize our findings. Future studies are warranted to confirm these findings in larger study populations. Furthermore, as with any other observational studies, we cannot completely exclude bias due to residual confounding although major potential confounders were adjusted for in the study.

In summary, we show that [1] fetal adipokines are associated with maternal factors such as BMI and GDM and there are ethnic and gender differences in cord adipokine levels in Asian neonates, and [2] cord blood leptin and adiponectin positively correlate with measures of neonatal abdominal fat accumulation. Further research is required to determine if these findings have an impact on early childhood abdominal fat accumulation.

\section{REFERENCES}

1. Kiess W, Petzold S, Topfer M, Garten A, Bluher S, Kapellen T, et al. Adipocytes and adipose tissue. Best Pract Res Clin Endocrinol Metab. 2008;22:135-53.

2. Flak JN, Myers MG Jr. Minireview: CNS Mechanisms of Leptin Action. Mol Endocrinol. 2016;30:3-12.

3. Farooqi IS, O'Rahilly S. Leptin: a pivotal regulator of human energy homeostasis. Am J Clin Nutr. 2009;89:980S-4S.

4. Parvaresh Rizi E, Teo Y, Leow MK, Venkataraman K, Khoo EY, Yeo CR, et al. Ethnic Differences in the Role of Adipocytokines Linking Abdominal Adiposity and Insulin Sensitivity Among Asians. J Clin Endocrinol Metab. 2015;100: 4249-56.
5. Karakosta P, Chatzi L, Plana E, Margioris A, Castanas E, Kogevinas M. Leptin levels in cord blood and anthropometric measures at birth: a systematic review and meta-analysis. Paediatr Perinat Epidemiol. 2011;25:150-63.

6. Ong KK, Ahmed ML, Sherriff A, Woods KA, Watts A, Golding J, et al. Cord blood leptin is associated with size at birth and predicts infancy weight gain in humans. ALSPAC Study Team. Avon Longitudinal Study of Pregnancy and Childhood. J Clin Endocrinol Metab. 1999;84:1145-8.

7. Karakosta P, Georgiou V, Fthenou E, Papadopoulou E, Roumeliotaki T, Margioris A, et al. Maternal weight status, cord blood leptin and fetal growth: a prospective mother-child cohort study (Rhea study). Paediatr Perinat Epidemiol. 2013;27: 461-71.

8. Karakosta P, Roumeliotaki T, Chalkiadaki G, Sarri K, Vassilaki M, Venihaki M, et al. Cord blood leptin levels in relation to child growth trajectories. Metabolism. 2016;65:874-82.

9. Tsai PJ, Yu CH, Hsu SP, Lee $\mathrm{YH}$, Chiou $\mathrm{CH}$, Hsu YW, et al. Cord plasma concentrations of adiponectin and leptin in healthy term neonates: positive correlation with birthweight and neonatal adiposity. Clin Endocrinol (Oxf). 2004;61:88-93.

10. Kayemba-Kay's S, Geary MP, Pringle J, Rodeck CH, Kingdom JC, Hindmarsh PC. Gender, smoking during pregnancy and gestational age influence cord leptin concentrations in newborn infants. Eur J Endocrinol. 2008;159:217-24.

11. Lawlor DA, West J, Fairley L, Nelson SM, Bhopal RS, Tuffnell D, et al. Pregnancy glycaemia and cord-blood levels of insulin and leptin in Pakistani and white British mother-offspring pairs: findings from a prospective pregnancy cohort. Diabetologia. 2014;57:2492-500.

12. Bouret SG. Nutritional programming of hypothalamic development: critical periods and windows of opportunity. Int J Obesity Supplements. 2012;2:S19-24. Suppl 2

13. Simpson J, Smith AD, Fraser A, Sattar N, Lindsay RS, Ring SM, et al. Programming of Adiposity in Childhood and Adolescence: Associations With Birth Weight and Cord Blood Adipokines. J Clin Endocrinol Metab. 2017;102:499-506.

14. Li LJ, Rifas-Shiman SL, Aris IM, Young JG, Mantzoros C, Hivert MF, et al. Associations of maternal and cord blood adipokines with offspring adiposity in Project Viva: is there an interaction with child age? Int J Obes (Lond). 2018;42: 608-17.

15. Meyer DM, Brei C, Stecher L, Much D, Brunner S, Hauner H. Leptin in Maternal Plasma and Cord Blood as a Predictor of Offspring Adiposity at 5 Years: a Followup Study. Obesity (Silver Spring). 2018;26:279-83.

16. Chaoimh CN, Murray DM, Kenny LC, Irvine AD, Hourihane JO, Kiely M. Cord blood leptin and gains in body weight and fat mass during infancy. Eur J Endocrinol. 2016;175:403-10.

17. Wang ZV, Scherer PE. Adiponectin, the past two decades. J Mol Cell Biol. 2016;8:93-100.

18. Chandran M, Phillips SA, Ciaraldi T, Henry RR. Adiponectin: more than just another fat cell hormone? Diabetes Care. 2003;26:2442-50.

19. Iliodromiti S, Sassarini J, Kelsey TW, Lindsay RS, Sattar N, Nelson SM. Accuracy of circulating adiponectin for predicting gestational diabetes: a systematic review and meta-analysis. Diabetologia. 2016;59:692-9.

20. Lowe LP, Metzger BE, Lowe WL Jr., Dyer AR, McDade TW, McIntyre HD. Inflammatory mediators and glucose in pregnancy: results from a subset of the Hyperglycemia and Adverse Pregnancy Outcome (HAPO) Study. J Clin Endocrinol Metab. 2010;95:5427-34.

21. Khoo CM, Sairazi S, Taslim S, Gardner D, Wu Y, Lee J, et al. Ethnicity modifies the relationships of insulin resistance, inflammation, and adiponectin with obesity in a multiethnic Asian population. Diabetes Care. 2011;34:1120-6.

22. Brynhildsen J, Sydsjo G, Blomberg M, Claesson IM, Theodorsson E, Nystrom F, et al. Leptin and adiponectin in cord blood from children of normal weight, overweight and obese mothers. Acta Paediatrica (Oslo, Norway: 1992). 2013;102: 620-4.

23. Aramesh MR, Dehdashtian M, Malekian A, ShahAli S, Shojaei K. Relation between fetal anthropometric parameters and cord blood adiponectin and high-sensitivity C-reactive protein in gestational diabetes mellitus. Arch Endocrinol Metab. 2017;61:228-32.

24. Zhang ZQ, Lu QG, Huang J, Jiao CY, Huang SM, Mao LM. Maternal and cord blood adiponectin levels in relation to post-natal body size in infants in the first year of life: a prospective study. BMC Preg Childbirth. 2016;16:189.

25. Meyer DM, Brei C, Stecher L, Much D, Brunner S, Hauner H. Cord blood and child plasma adiponectin levels in relation to childhood obesity risk and fat distribution up to 5 y. Pediatr Res. 2017;81:745-51.

26. Kamoda $T$, Saitoh $H$, Saito $M$, Sugiura $M$, Matsui A. Serum adiponectin concentrations in newborn infants in early postnatal life. Pediatr Res. 2004;56:690-3.

27. Kotani Y, Yokota I, Kitamura S, Matsuda J, Naito E, Kuroda Y. Plasma adiponectin levels in newborns are higher than those in adults and positively correlated with birth weight. Clin Endocrinol (Oxf). 2004;61:418-23. 
28. Sivan E, Mazaki-Tovi S, Pariente C, Efraty Y, Schiff E, Hemi R, et al. Adiponectin in human cord blood: relation to fetal birth weight and gender. J Clin Endocrinol Metab. 2003;88:5656-60

29. Hinkle SN, Rawal S, Liu D, Chen J, Tsai MY, Zhang C. Maternal adipokines longitudinally measured across pregnancy and their associations with neonatal size, length, and adiposity. Int J Obes (Lond). 2019;43:1422-34.

30. Ong GK, Hamilton JK, Sermer M, Connelly PW, Maguire G, Zinman B, et al. Maternal serum adiponectin and infant birthweight: the role of adiponectin isoform distribution. Clin Endocrinol (Oxf). 2007;67:108-14.

31. Aye IL, Powell TL, Jansson T. Review: Adiponectin-the missing link between maternal adiposity, placental transport and fetal growth? Placenta. 2013;34: S40-5. Suppl

32. Qiao L, Yoo HS, Madon A, Kinney B, Hay WW Jr., Shao J. Adiponectin enhances mouse fetal fat deposition. Diabetes. 2012;61:3199-207.

33. Despres JP. Body fat distribution and risk of cardiovascular disease: an update. Circulation. 2012;126:1301-13.

34. Kelishadi $R$, Mirmoghtadaee $P$, Najafi $H$, Keikha M. Systematic review on the association of abdominal obesity in children and adolescents with cardiometabolic risk factors. J Res Med Sci: Off J Isfahan Univer Med Sci. 2015;20: 294-307.

35. Suliga E. Visceral adipose tissue in children and adolescents: a review. Nutr Res Rev. 2009:22:137-47.

36. Bajaj HS, Pereira MA, Anjana RM, Deepa R, Mohan V, Mueller NT, et al. Comparison of relative waist circumference between Asian Indian and US adults. J Obes. 2014;2014:461956.

37. Tint MT, Fortier MV, Godfrey KM, Shuter B, Kapur J, Rajadurai VS, et al. Abdominal adipose tissue compartments vary with ethnicity in Asian neonates: Growing Up in Singapore Toward Healthy Outcomes birth cohort study. Am J Clin Nutr. 2016;103:1311-7.

38. Yajnik CS, Lubree HG, Rege SS, Naik SS, Deshpande JA, Deshpande SS, et al. Adiposity and hyperinsulinemia in Indians are present at birth. J Clin Endocrinol Metab. 2002;87:5575-80.

39. Strauss RS, Pollack HA. Epidemic increase in childhood overweight, 1986-1998. Jama. 2001;286:2845-8.

40. Weiss R, Dziura J, Burgert TS, Tamborlane WV, Taksali SE, Yeckel CW, et al. Obesity and the metabolic syndrome in children and adolescents. N Engl J Med. 2004;350:2362-74.

41. Soh SE, Tint MT, Gluckman PD, Godfrey KM, Rifkin-Graboi A, Chan YH, et al. Cohort profile: Growing Up in Singapore Towards healthy Outcomes (GUSTO) birth cohort study. Int J Epidemiol. 2014:43:1401-9.

42. Pacific WHOROftW. The Asia-Pacific perspective: redefining obesity and its treatment.: Sydney: Health Communications Australia; 2000.

43. World Health $\mathrm{O}$. Definition, diagnosis and classification of diabetes mellitus and its complications: report of a WHO consultation. Part 1, Diagnosis and classification of diabetes mellitus. Geneva: World Health Organization; 1999.

44. Institute of Medicine Committee on Nutritional Status During $\mathrm{P}$, Lactation. Nutrition During Pregnancy: Part I Weight Gain: Part II Nutrient Supplements. Washington (DC): National Academies Press (US) Copyright $\odot 1990$ by the National Academy of Sciences; 1990.

45. Aris IM, Soh SE, Tint MT, Liang S, Chinnadurai A, Saw SM, et al. Body fat in Singaporean infants: development of body fat prediction equations in Asian newborns. Eur J Clin Nutr. 2013;67:922-7.

46. Hawkes $C P$, Hourihane JO, Kenny LC, Irvine AD, Kiely M, Murray DM. Gender- and gestational age-specific body fat percentage at birth. Pediatrics. 2011;128: e645-51.

47. Urlando A, Dempster P, Aitkens S. A new air displacement plethysmograph for the measurement of body composition in infants. Pediatr Res. 2003:53:486-92.

48. Benjamini Y, Hochberg Y. Controlling the False Discovery Rate: A Practical and Powerful Approach to Multiple. Journal of the Royal Statistical Society: Series B (Methodological). 1995;57:289-300.

49. Gross GA, Solenberger T, Philpott T, Holcomb WL Jr., Landt M. Plasma leptin concentrations in newborns of diabetic and nondiabetic mothers. Am J Perinatol. 1998;15:243-7.

50. Persson B, Westgren M, Celsi G, Nord E, Ortqvist E. Leptin concentrations in cord blood in normal newborn infants and offspring of diabetic mothers. Horm Metab Res. 1999;31:467-71.

51. Cortelazzi D, Corbetta S, Ronzoni S, Pelle F, Marconi A, Cozzi V, et al. Maternal and foetal resistin and adiponectin concentrations in normal and complicated pregnancies. Clin Endocrinol (Oxf). 2007;66:447-53.

52. Aris IM, Soh SE, Tint MT, Liang S, Chinnadurai A, Saw SM, et al. Effect of maternal glycemia on neonatal adiposity in a multiethnic Asian birth cohort. J Clin Endocrinol Metab. 2014;99:240-7.

53. Luo ZC, Nuyt AM, Delvin E, Fraser WD, Julien P, Audibert F, et al. Maternal and fetal leptin, adiponectin levels and associations with fetal insulin sensitivity. Obesity (Silver Spring). 2013;21:210-6.
54. Forhead AJ, Fowden AL. The hungry fetus? Role of leptin as a nutritional signal before birth. J Physiol. 2009:587:1145-52.

55. Mantzoros CS, Rifas-Shiman SL, Williams CJ, Fargnoli JL, Kelesidis T, Gillman MW. Cord blood leptin and adiponectin as predictors of adiposity in children at 3 years of age: a prospective cohort study. Pediatrics. 2009;123:682-9.

56. Weyermann M, Beermann $\mathrm{C}$, Brenner $\mathrm{H}$, Rothenbacher D. Adiponectin and leptin in maternal serum, cord blood, and breast milk. Clin Chem. 2006;52:2095-102.

57. Mazaki-Tovi S, Kanety H, Pariente C, Hemi R, Schiff E, Sivan E. Cord blood adiponectin in large-for-gestational age newborns. Am J Obstet Gynecol. 2005;193:1238-42.

58. Pardo IM, Geloneze B, Tambascia MA, Barros-Filho AA. Hyperadiponectinemia in newborns: relationship with leptin levels and birth weight. Obes Res. 2004;12:521-4.

59. Frederiksen L, Nielsen TL, Wraae K, Hagen C, Frystyk J, Flyvbjerg A, et al. Subcutaneous rather than visceral adipose tissue is associated with adiponectin levels and insulin resistance in young men. J Clin Endocrinol Metab. 2009:94:4010-5.

60. Nakano Y, Itabashi K, Sakurai M, Aizawa M, Dobashi K, Mizuno K. Accumulation of subcutaneous fat, but not visceral fat, is a predictor of adiponectin levels in preterm infants at term-equivalent age. Early Human Dev. 2014;90:213-7.

61. Araki S, Dobashi K, Kubo K, Asayama K, Shirahata A. High molecular weight, rather than total, adiponectin levels better reflect metabolic abnormalities associated with childhood obesity. J Clin Endocrinol Metab. 2006;91:5113-6.

62. Nishimura R, Morimoto A, Matsudaira T, Miyashita $Y$, Sano H, Shirasawa T, et al. Ratio of high-, medium-, and low-molecular weight serum adiponectin to the total adiponectin value in children. J Pediatrics. 2007;151:545-7, 7.e1-2.

63. Odden N, Mørkrid L. High molecular weight adiponectin dominates in cord blood of newborns but is unaffected by pre-eclamptic pregnancies. Clin Endocrinol (Oxf). 2007;67:891-6.

64. Hibino S, Itabashi K, Nakano Y, Inoue M, Tanaka D, Maruyama T. Longitudinal changes in high molecular weight serum adiponectin levels in healthy infants. Pediatr Res. 2009;65:363-6.

\section{ACKNOWLEDGEMENTS}

The GUSTO study group includes Allan Sheppard, Amutha Chinnadurai, Anne Eng Neo Goh, Anne Rifkin Graboi, Anqi Qiu, Arijit Biswas, Bee Wah Lee, Birit F.P. Broekman, Boon Long Quah, Borys Shuter, Chai Kiat Chng, Cheryl Ngo, Choon Looi Bong, Christiani Jeyakumar Henry, Claudia Chi, Cornelia Yin Ing Chee, Yam Thiam Daniel Goh, Doris Fok, E Shyong Tai, Elaine Tham, Elaine Quah Phaik Ling, Evelyn Chung Ning Law, Evelyn Xiu Ling Loo, Fabian Yap, Falk Mueller-Riemenschneider, George Seow Heong Yeo, Helen Chen, Heng Hao Tan, Hugo P S van Bever, Iliana Magiati, Inez Bik Yun Wong, Ivy Yee-Man Lau, Izzuddin Bin Mohd Aris, Jeevesh Kapur, Jenny L. Richmond, Jerry Kok Yen Chan, Joanna D. Holbrook, Joanne Yoong, Joao N. Ferreira., Jonathan Tze Liang Choo, Jonathan Y. Bernard, Joshua J. Gooley, Keith M. Godfrey, Kenneth Kwek, Kok Hian Tan, Krishnamoorthy Niduvaje, Kuan Jin Lee, Leher Singh, Lieng Hsi Ling, Lin Lin Su, Ling-Wei Chen, Lourdes Mary Daniel, Lynette P Shek, Marielle V. Fortier, Mark Hanson, Mary Foong-Fong Chong, Mary Rauff, Mei Chien Chua, Melvin Khee-Shing Leow, Michael Meaney, Mya Thway Tint, Neerja Karnani, Ngee Lek, Oon Hoe Teoh, P. C. Wong, Paulin Tay Straughan, Peter D. Gluckman, Pratibha Agarwal, Queenie Ling Jun Li, Rob M. van Dam, Salome A. Rebello, SeangMei Saw, See Ling Loy, S. Sendhil Velan, Seng Bin Ang, Shang Chee Chong, Sharon $\mathrm{Ng}$, Shiao-Yng Chan, Shirong Cai, Shu-E Soh, Sok Bee Lim, Stella Tsotsi, Chin-Ying Stephen Hsu, Sue Anne Toh, Swee Chye Quek, Victor Samuel Rajadurai, Walter Stunkel, Wayne Cutfield, Wee Meng Han, Wei Wei Pang, Yap-Seng Chong, Yin Bun Cheung, Yiong Huak Chan and Yung Seng Lee. The authors thank Esther Mok for performing the cord blood leptin and adiponectin assays and Bernett Lee for statistical analyses of the cord blood leptin and adiponectin data. The funding sources had no role in the design and conduct of the study; collection, management, analysis, and interpretation of the data; preparation, review, or approval of the paper; and decision to submit the paper for publication. This research is supported by the Singapore National Research Foundation under its Translational and Clinical Research (TCR) Flagship Programme and administered by the Singapore Ministry of Health's National Medical Research Council (NMRC), Singapore- NMRC/TCR/004-NUS/2008; NMRC/TCR/012-NUHS/2014. Additional funding is provided by the Singapore Institute for Clinical Sciences, Agency for Science, Technology and Research (A*STAR), Singapore including Industry Alignment Fund Pre-Positioning Programme (IAF-PP), $\mathrm{H} 17 / 01 / \mathrm{a} 0 / 005$.

\section{AUTHOR CONTRIBUTIONS}

KT, MTT and NK had full access to all the data in the study and take responsibility for the integrity of the data and the accuracy of the data analysis. Study concept and design: NK, MTT, KT. Acquisition and analysis image data: MTT, MVF. Acquisition and 
analysis PEA POD data: MTT. Acquisition and analysis adipokine data: AL. Statistical analysis and interpretation of data: MTT, KT. Drafting of the paper: KT, MTT. Critical revision of the paper for important intellectual content: NK, JGE, NM, YSC, FY, KHT, KMG, YSL, SYCh. Study supervision: NK, JGE.

\section{COMPETING INTERESTS}

YSC, KMG, SYC and NK are part of an academic consortium that has received research funding from companies selling nutritional products. KMG, SYC and NK have received reimbursement for speaking at conferences sponsored by companies selling nutritional products. KMG is supported by the UK Medical Research Council (MC_UU_12011/4), National Institute for Health Research (NIHR Senior Investigator (NF-SI-0515-10042), NIHR Southampton 1000DaysPlus Global Nutrition Research Group and NIHR Southampton Biomedical Research (entre) and by the European Union (Erasmus + Programme Early Nutrition eAcademy Southeast Asia-573651-EPP1-2016-1-DE-EPPKA2-CBHE-JP). All other authors declare no financial relationships with any organizations that might have an interest in the submitted work in the previous 3 years, and no other relationships or activities that could appear to have influenced the submitted work.

\section{ADDITIONAL INFORMATION}

Supplementary information The online version contains supplementary material available at https://doi.org/10.1038/s41366-021-00975-3.
Correspondence and requests for materials should be addressed to Neerja Karnani.

Reprints and permission information is available at http://www.nature.com/ reprints

Publisher's note Springer Nature remains neutral with regard to jurisdictional claims in published maps and institutional affiliations.

Attribution 4.0 International License, which permits use, sharing, adaptation, distribution and reproduction in any medium or format, as long as you give appropriate credit to the original author(s) and the source, provide a link to the Creative Commons license, and indicate if changes were made. The images or other third party material in this article are included in the article's Creative Commons license, unless indicated otherwise in a credit line to the material. If material is not included in the article's Creative Commons license and your intended use is not permitted by statutory regulation or exceeds the permitted use, you will need to obtain permission directly from the copyright holder. To view a copy of this license, visit http://creativecommons. org/licenses/by/4.0/.

(c) The Author(s) 2021 